\title{
Lifetime risk assessment in cholesterol management among hypertensive patients: observational cross-sectional study based on electronic health record data
}

Aapo Tahkola ${ }^{1,2^{*}}$, Päivi Korhonen ${ }^{3}$, Hannu Kautiainen ${ }^{4}$, Teemu Niiranen ${ }^{5,6}$ and Pekka Mäntyselkä ${ }^{1,7}$

\begin{abstract}
Background: In hypertensive patients, reducing plasma low-density lipoprotein cholesterol level (LDL-C) is one of the main interventions for preventing chronic cardiovascular diseases (CVD). However, LDL-C control remains generally insufficient, also in patients with hypertension. We analyzed Electronic Health Record (EHR) data of 7117 hypertensive patients to find the most potential age and sex subgroups in greatest need for improvement in real life dyslipidemia treatment. Taking into account the current discussion on lifetime CVD risk, we focused on the age dependence in LDL-C control.

Methods: In this observational cross-sectional study, based on routine electronic health record (EHR) data, we investigated LDL-C control of hypertensive, non-diabetic patients without renal dysfunction or CVD, aged 30 years or more in Finnish primary care setting.

Results: More than half (54\% of women and $53 \%$ of men) of untreated patients did not meet the LDL-C target of $<3$ $\mathrm{mmol} / \mathrm{l}$ and one third (35\% of women and $33 \%$ of men) of patients did not reach the target even with the lipidlowering medication (LLM). Furthermore, higher age was strongly associated with better LDL-C control $(p<0.001)$ and lower LDL-C level $(p<0.001)$ in individuals with and without LLM. Higher age was also strongly associated with LLM prescription $(p<0.001)$. In total, about half of the patients were on LLM (53\% of women and $51 \%$ of men).

Conclusions: Our findings indicate that dyslipidemia treatment among Finnish primary care hypertensive patients is generally insufficient, particularly in younger age groups who might benefit the most from CVD risk reduction over time. Clinicians should probably rely more on the lifetime risk of CVD, especially when treating working age hypertensive patients.
\end{abstract}

Keywords: Dyslipidemia, Hypertension, Lifetime risk, Lipid-lowering medication, LDL-C, Target

\footnotetext{
* Correspondence: aapo.tahkola@jkl.fi

${ }^{1}$ University of Eastern Finland, Institute of Public Health and Clinical Nutrition,

Kuopio, Finland

${ }^{2}$ Health Centre of Jyväskylä Cooperation Area, Jyväskylä, Finland

Full list of author information is available at the end of the article
}

(c) The Author(s). 2020 Open Access This article is licensed under a Creative Commons Attribution 4.0 International License, which permits use, sharing, adaptation, distribution and reproduction in any medium or format, as long as you give appropriate credit to the original author(s) and the source, provide a link to the Creative Commons licence, and indicate if changes were made. The images or other third party material in this article are included in the article's Creative Commons licence, unless indicated otherwise in a credit line to the material. If material is not included in the article's Creative Commons licence and your intended use is not permitted by statutory regulation or exceeds the permitted use, you will need to obtain permission directly from the copyright holder. To view a copy of this licence, visit http://creativecommons.org/licenses/by/4.0/ The Creative Commons Public Domain Dedication waiver (http://creativecommons.org/publicdomain/zero/1.0/) applies to the data made available in this article, unless otherwise stated in a credit line to the data. 


\section{Background}

Dyslipidemia increases the risk for cardiovascular diseases (CVD) considerably, especially when combined with other risk factors, such as hypertension [1, 2]. The relationship between dyslipidemia and CVD is particularly strong with plasma low-density lipoprotein cholesterol level (LDL-C) as every $1 \mathrm{mmol} / \mathrm{L}$ increase in LDL-C is associated with $28 \%$ risk increase in coronary heart disease mortality [3]. Reducing LDL-C is therefore one of the central focuses in preventing CVD, also in hypertensive patients.

Treatment decisions should always be based on the total risk for CVD. The majority of hypertensive patients without CVD, diabetes or moderate to severe chronic kidney disease (CKD; stages 3-5) have low to moderate risk for CVD [3]. According to the 2016 European Society of Cardiology (ESC) and the European Atherosclerosis Society (EAS) Guidelines for the Management of Dyslipidaemias, the target for individuals at low or moderate total CVD risk for treatment is $\mathrm{LDL}-\mathrm{C}<3 \mathrm{mmol} / \mathrm{l}$ [3]. Lifestyle changes are essential as a first approach but with hypertensive patients, who have moderate-high CV risk, lipid-lowering therapy is justified [4-9].

Recent studies demonstrate that LDL-C control remains quite insufficient in Finland and other European countries, even among high CVD risk populations $[10,11]$.. LDL-C control seems to be especially poor in younger age groups in many countries and patient groups [11-14]. This is an important signal, given the accumulating evidence on the benefits of adequate LDL-C - control over time and growing interest on life-long prevention of CVD [15-19].

The aim of this study was to analyze routine EHR data of hypertensive patients in order to find the most potential age and sex subgroups in greatest need for improvement in dyslipidemia treatment. We were particularly interested on potential age dependence in LDL-C control based on the viewpoint of lifetime CVD risk.

\section{Methods}

In this observational cross-sectional study using routinely collected health care data together with laboratory data, we investigated the level of plasma LDL-C among Finnish hypertensive patients. The most recent LDL-C measurement available for each individual patient was used in the analysis. Permission for this study was obtained from the research committee of Health Centre of Jyväskylä Cooperation Area and it complies with the Declaration of Helsinki. Ethics approval was deemed unnecessary according to Finnish legislation [20].

\section{Setting}

The study was conducted in Finnish public primary care setting in Jyväskylä area. The comprehensive electronic health record data of total population of 155,411 was screened on 24th of May, 2016. The data included laboratory and medication data between between January 2011 and December 2015.

\section{Patients}

We included all hypertensive patients aged 30 years or more. The identification of patients was based on the personal identity code. Every citizen of Finland has a personal identity code that remains unchanged throughout person's lifetime. We included patients with presence of $\geq 1$ claims with International Classification of Diseases, Tenth Revision (ICD-10) code for essential hypertension (I10.xx) [21]. We included diagnostic codes starting from the year 2011. Since the diagnostic criteria for hypertension has changed from time to time and the diagnoses of hypertension for individual study patients has been made over a relatively long time period, it is not possible to define specific diagnostic values for hypertension in our study patients. Exclusion criteria were: (1) diabetes (E10.xxE14.xx), (2) cardiovascular disease (ischemic heart disease I20.xx - I25.xx, stroke I60.xx - I63.xx, peripheral artery disease I70.xx - I79.xx), (3) severe renal dysfunction and (4) age under 30 years. The presence of severe renal dysfunction was based on an estimated glomerulus filtration rate $(\mathrm{eGFR}<30 \mathrm{ml} / \mathrm{min} / 1.73 \mathrm{~m} 2)$ [22]. Patients with diabetes were excluded because our data did not allow us to identify patients with microvascular diabetic complications and, therefore, setting the right target level for diabetics was not possible. Patients $<30$ years of age were excluded because the small amount of patients $(n=71)$ made it impossible to carry out a feasible analysis. The screening process is presented in Fig. 1. LDL-C target was considered to be $<3 \mathrm{mmol} / \mathrm{l}$, according to European and Finnish treatment guidelines [3, 23].

\section{Statistical analyses}

The characteristics are presented as means with standard deviation (SD) for continuous variables and as frequencies with percentages for categorical variables, according to gender. Statistical comparisons between groups were done using chi-square test, t-test and generalized linear models (analysis of variance and logistic models). Tests for interactions between LLM-group or gender and age group were conducted by adding a multiplicative term between group or gender and the age group. The normality of the variables was tested by using the Shapiro-Wilk W test. Adjustment for multiple comparisons was considered unnecessary. The Stata 14.1, StataCorp LP (College Station, TX, USA) statistical package was used for the analysis.

\section{Results}

A total of 7117 hypertensive patients were identified from the EHR data. Table 1 displays the patients' co- 


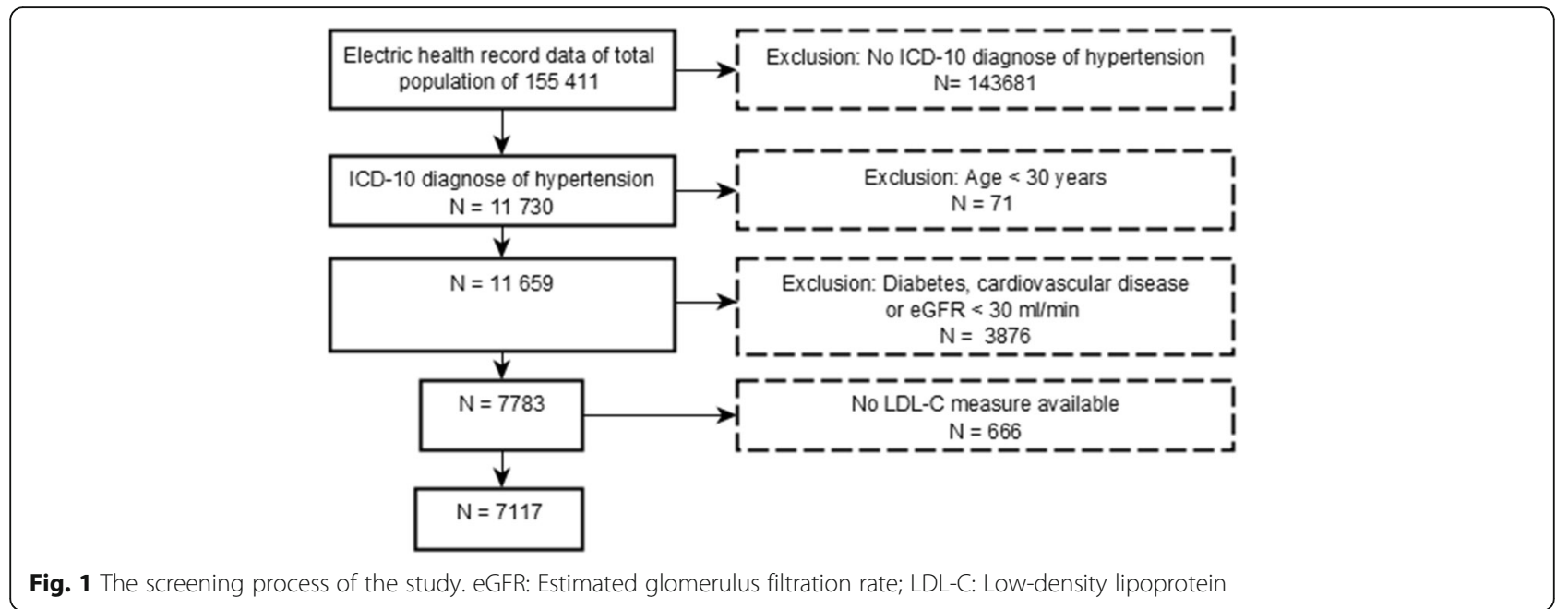

morbidities, medication usage and LDL-C levels according to gender.

In total, $65 \%$ of hypertensive women and $67 \%$ of hypertensive men treated with LLM reached the LDL-C target $<3$ $\mathrm{mmol} / \mathrm{l}$. Without LLM, the proportion of patients reaching the target was even lower ( $46 \%$ of women and $47 \%$ of men). Of all patients, $56 \%$ of hypertensive patients reached the LDL$\mathrm{C}$ target. The proportions of individuals reaching treatment target with and without medication is presented in Table 2.

The proportion of women and men reaching the LDLcholesterol target level rose statistically linearly with increasing age ( $p$-value for linearity $<0.001)$. The proportion of patients receiving LDL-C target was higher with the patients with LLM, with the exception of two subgroups: women and men aged 30-49 years, and among men at least 80 years of age (Fig. 2).

Accordingly, the mean plasma LDL-cholesterol level decreased linearly with increasing age whether LLM was prescribed or not ( $p$-value for linearity < 0.001) (Fig. 3). In the age group of 30-49 years, LLM was prescribed to $10.3 \%$ of the women and $24.5 \%$ of the men. The percentage of patients with LLM rose linearly across older age groups being $63.1 \%$ in women and $59.4 \%$ in men aged $70-79$ years (p-value for linearity < 0.001) (Fig. 4).

Table 1 Characteristics of study patients

\begin{tabular}{|c|c|c|c|}
\hline & Women $N=4344$ & Men $N=2773$ & $P$-value \\
\hline \multicolumn{4}{|l|}{ Demographics } \\
\hline Mean age (years), mean (SD) & $70(12)$ & $66(12)$ & $<0.001$ \\
\hline \multicolumn{4}{|l|}{ Medication (ATC), n (\%) } \\
\hline Lipid-lowering medication (C10) & $2310(53)$ & $1400(50)$ & 0.027 \\
\hline Other cardiac therapy e.g. antiarrhythmics, nitrates (C01) & $936(22)$ & $429(15)$ & $<0.001$ \\
\hline ACE-inhibitors, Angiotensin II antagonists (C09) & $3531(81)$ & $2330(84)$ & 0.003 \\
\hline Diuretics (C03) & $1370(32)$ & $538(19)$ & $<0.001$ \\
\hline Beta blockers (C07) & $2477(57)$ & $1312(47)$ & $<0.001$ \\
\hline Calcium Channel Blockers (C08) & $2150(49)$ & $1379(50)$ & 0.85 \\
\hline Other antihypertensives (CO2) & $114(3)$ & $73(3)$ & 0.97 \\
\hline \multicolumn{4}{|l|}{ Co-morbidity (ICD-10), n (\%) } \\
\hline Heart failure (150) & $95(2)$ & $31(1)$ & $<0.001$ \\
\hline Atrial fibrillation and flutter (148) & $295(7)$ & $207(7)$ & 0.28 \\
\hline \multicolumn{4}{|l|}{ Plasma LDL-C level, mean (SD) } \\
\hline All & $2.88(0.88)$ & $2.85(0.88)$ & $<0.001^{a}$ \\
\hline With LLM & $2.75(0.97)$ & $2.68(0.98)$ & $<0.001^{\mathrm{a}}$ \\
\hline Without LLM & $3.03(0.73)$ & $3.01(0.73)$ & $0.25^{\mathrm{a}}$ \\
\hline
\end{tabular}

Abbreviations. LLM lipid lowering medication, LDL-C low-density lipoprotein

${ }^{\text {a Adjusted for age }}$ 
Table 2 Proportion of individuals reaching LDL-C target

\begin{tabular}{|c|c|c|c|c|c|c|}
\hline & Age $30-49$ & Age 50-59 & Age 60-69 & Age 70-79 & Age 80 - & Total \\
\hline \multicolumn{7}{|c|}{ LDL-C TARGET REACHED } \\
\hline \multicolumn{7}{|c|}{ Women without LLM } \\
\hline Yes, n (\%) & $119(50.4)$ & $132(37.5)$ & $250(41.5)$ & $235(47.2)$ & $192(55.7)$ & $928(45.6)$ \\
\hline \multicolumn{7}{|c|}{ Women with LLM } \\
\hline Yes, n (\%) & $15(55.6)$ & $75(48.1)$ & $436(62.1)$ & $595(70.0)$ & $383(66.6)$ & $1504(65.1)$ \\
\hline \multicolumn{7}{|c|}{ Men without LLM } \\
\hline Yes, n (\%) & $80(41.2)$ & $100(36.8)$ & $207(46.1)$ & $175(54.4)$ & $90(66.2)$ & $652(47.5)$ \\
\hline \multicolumn{7}{|c|}{ Men with LLM } \\
\hline Yes, n (\%) & $27(42.9)$ & $90(54.9)$ & $362(68.2)$ & $337(71.6)$ & $121(70.8)$ & $937(66.9)$ \\
\hline \multicolumn{7}{|c|}{ LIPID-LOWERING MEDICATION } \\
\hline \multicolumn{7}{|l|}{ Women } \\
\hline Yes, n (\%) & $27(10.3)$ & $156(30.7)$ & $702(53.8)$ & $850(63.0)$ & $575(62.5)$ & $2310(53.2)$ \\
\hline \multicolumn{7}{|l|}{ Men } \\
\hline Yes, n (\%) & $63(24.5)$ & 164 (37.6) & $531(54.2)$ & 471 (59.4) & 171 (55.7) & $1400(50.5)$ \\
\hline
\end{tabular}

Abbreviations. LDL-C low-density lipoprotein, LLM lipid-lowering medication

\section{Discussion}

Our study indicates that LDL-C control among Finnish hypertensive patients is insufficient, especially among younger patients. Without LLM, more than half of patients did not reach LDL-C target and even with medication, one third of patients did not meet the target. Furthermore, the proportion of individuals reaching LDL-C target seems to be lowest among working age patients who might benefit the most from CVD risk reduction over time $[17,18]$.

It is clear that younger patients have significantly lower total CVD risk than older patients when assessed using conventional short-term (generally 10-year) risk estimates. Due to current emphasis on short-term risk estimates, clinicians often choose not to initiate effective dyslipidemia treatment when short-term risk is low due to young age. It is remarkable, however, that all our study patients had at least one major CVD risk factor (treatment for hypertension), indicating that proper treatment of another major risk factor (hypercholesterolemia) would decrease the lifetime risk of CVD considerably [18].

Furthermore, it is challenging to rationalize why patients who are on LLM treatment are not treated to a
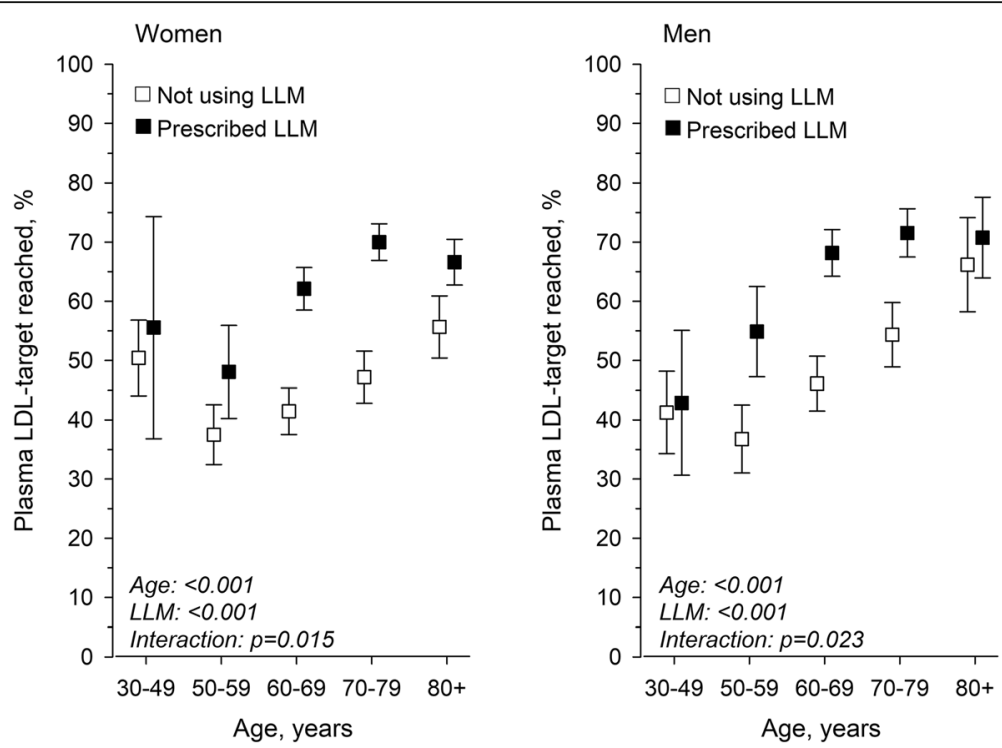

Fig. 2 Association between age and proportion reaching LDL-C target. LDL-C: Low-density lipoprotein; LLM: Lipid-lowering medication 

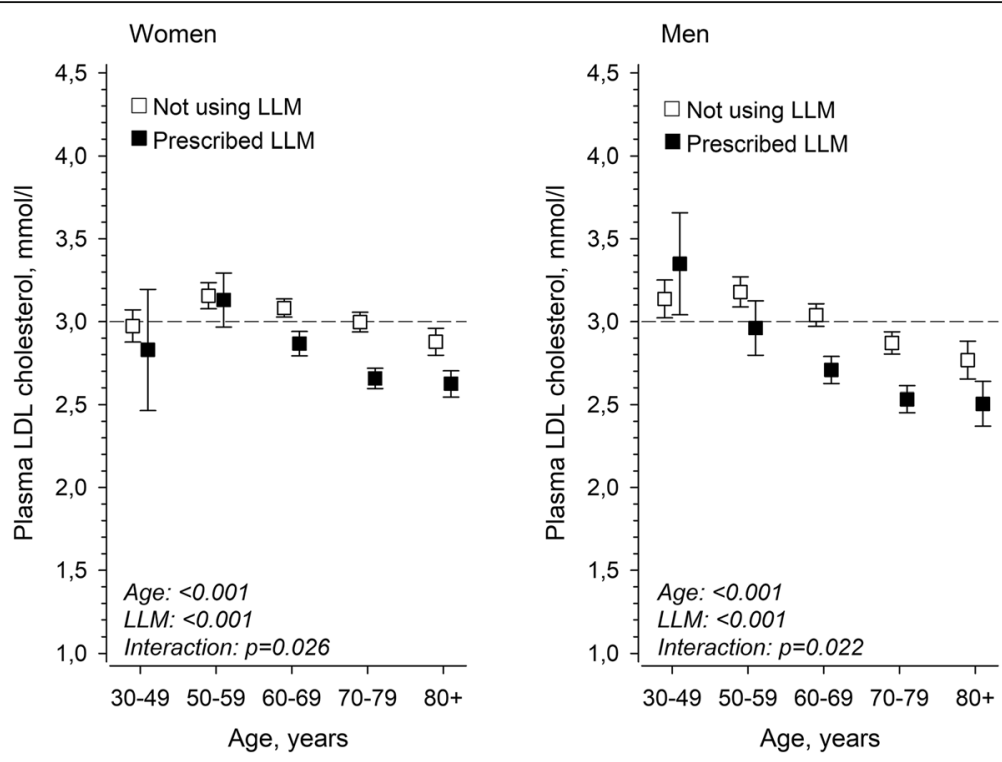

Fig. 3 Association between age and plasma LDL-C levels. LDL-C: Low-density lipoprotein; LLM: Lipid-lowering medication

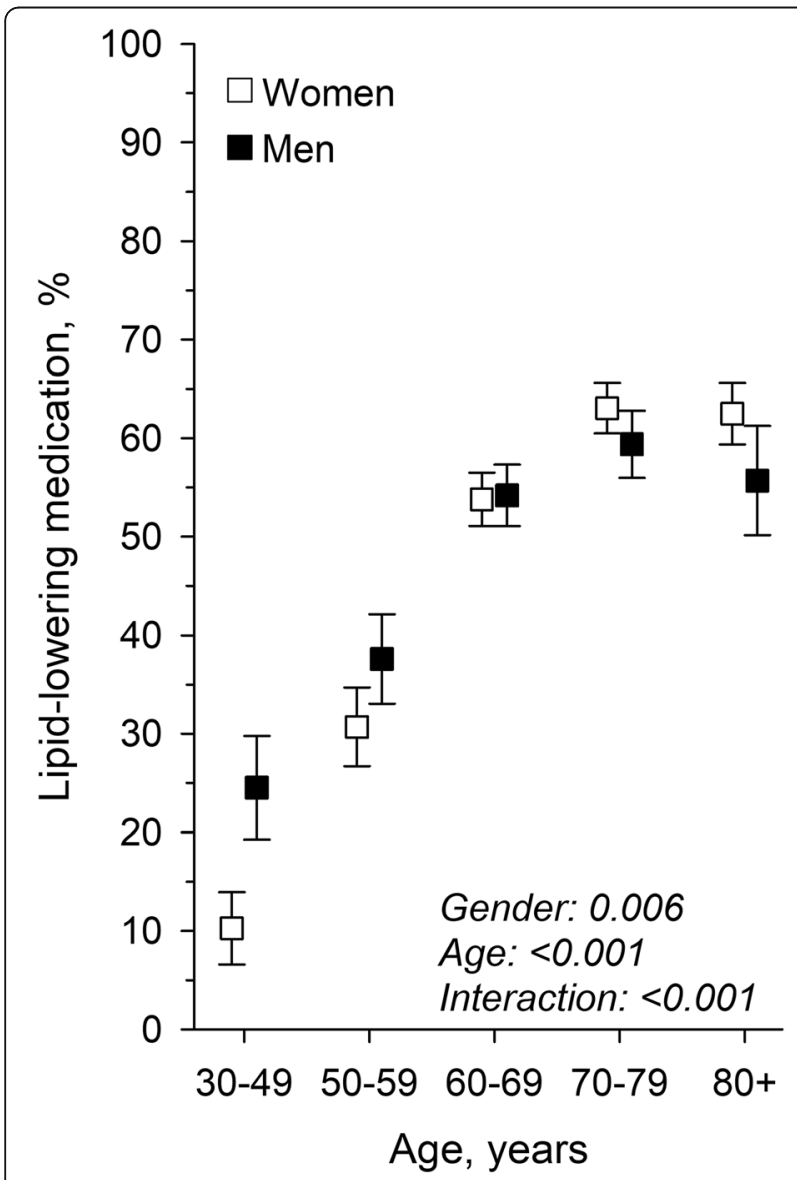

Fig. 4 Association between age and lipid-lowering medication use. LDL-C: Low-density lipoprotein; LLM: Lipid-lowering medication relatively easy-to-reach LDL-C target of $<3 \mathrm{mmol} / \mathrm{l}$, regardless of age. With these individuals, the question is not "Should we treat cholesterol with drugs or not?" but rather: "Should we use the chosen medication properly or not?". Poor medication adherence often forms a barrier for successful therapy, together with clinical inertia $[3,24,25]$. We argue, however, that lack of sufficient, individual physician feed-back and robust leadership engagement to overcome clinical inertia are also major, but modifiable reasons for this failure. Computerized decision support systems could offer one way to drive change for the better, but feedback alone is not sufficient for system-wide change [26, 27].

\section{Strengths and limitations}

This study has several strengths. To our knowledge, this is the first article to focus on age dependence in LDL-C control among hypertensive patients. Furthermore, Finland has robust public health care and majority of hypertensive patients are treated in public primary health care [28]. To conduct the study, we were able to rely on comprehensive public health care health records of a total population of over 155,000 individuals living in Central Finland (http:// pxnet2.stat.fi/PXWeb/pxweb/en/StatFin/StatFin_vrm_ vaerak/010_vaerak_tau_123.px/?rxid=ada87756-a322-4f53b48e-78fdc85edfa2). Hence, the EHR database used in our study includes the majority of all hypertensive patients treated in this area.

Our study has also some limitations that are worth discussion. This was an observational cross-sectional study using routinely collected health care data together with laboratory data. These data sources have naturally several limitations. First, they do not provide sufficient information to assess total individual CVD risk. 
Therefore, we focused only in hypertensive population without CVD, diabetes or severe renal dysfunction. It is therefore reasonable to assume that LDL-C treatment targets of the general population are used in these patients [3, 9, 23]. Second, these data sources lack trustworthy information on smoking and current blood pressure status. This would be a major problem in prognostic study setting, but is not essential when studying the treatment status of an independent risk factor, such as LDL-C. Smoking and the blood pressure level of hypertensive patients do not change the LDL-C target levels, either. Third, the coverage and accuracy of diagnostic codes is never perfect, and may have resulted in misclassification of some patients, especially diabetics. However, the EHR data used in the study has also been a basis of a rigorous quality measurement system for several years and the accuracy of diagnostic codes has therefore enhanced remarkably. When analysing the data, we were also able to perform multiple chart reviews and found no signs of major misclassification. It is also possible that better target achievement in older age groups is partly due to more frequent use of health services due to increased multimorbidity, but we were not able to detect and compare our findings with the use of health services. Furthermore, it is probable, that some working age patients visit both primary and occupational health care and their LDL-C level may thus be treated to target in occupational health care after being first measured in primary health care. Finally, the status of LLM treatment in this study was based on up-to-date information of LLM prescription but our data does not provide reliable information on the adherence to medication or non-medical treatment of dyslipidemia.

\section{Comparison with existing literature}

Some previous studies have observed a similar age dependent trend in the proportion of individuals reaching LDL-C target [11-14]. It might seem reasonable to assume that physiological changes of aging could explain the better LDL-C control among older patients. However, it has been shown that both plasma LDL-C and total cholesterol levels increase progressively after age of 20 years [29,30]. One explanation seems to be better LLM adherence among older patients [31]. However, the pattern of age-dependent increase in LDL-C is different between men and women and may thus, at least partly, explain the somewhat weaker association of age and LDL-C -levels among women [32].

Earlier, the gender differences in the proportion of men and women reaching LDL-C target have already raised a need to pay special attention to treatment of dyslipidemia in women [14]. Our results suggest that it is now time to pay more attention to younger dyslipidemia patients, as well. This is further emphasized by earlier research findings indicating that younger age is also associated with lower awareness and treatment rates of elevated blood pressure in Finland [33]. Lifetime risk estimates of CVD are developing rapidly and open access lifetime risk calculators are already available [17, 34]. At least one on-going randomised, controlled clinical study is currently investigating 10-year benefits of statin treatment in 35-59 year-old patients with LDLC $>1.8 \mathrm{mmol} / \mathrm{L}$ and at least one risk factor other than dyslipidemia [16].

\section{Conclusions}

Our findings suggest that working age patients might be the most potential subgroup to enhance LDL-C control and CVD risk reduction among Finnish hypertensive primary health are patients. Focusing more on the lifetime risk of CVD might help primary care physicians to make better informed decisions on dyslipidemia treating among younger hypertensive patients. This should, however, be further examined in different patient populations.

\section{Abbreviations}

CVD: Cardiovascular diseases; CKD: Chronic kidney disease; EAS: European Atherosclerosis Society; eGFR: Estimated glomerulus filtration rate (CKD-EPI equation); EHR: Electronic health record; ESC: European Society of Cardiology; LDL-C: Low-density lipoprotein; LLM: Lipid-lowering medication

\section{Acknowledgements}

We thank Jyväskylä Cooperation Area Health Center for enabling this study and everyone involved in the study arrangements.

\section{Authors' contributions}

All the authors participated in the design of the study. AT drafted the manuscript and had the main responsibility of coordinating the study. HK created the statistical analysis plan and was responsible for statistical analyses. AT, PM, PK and TN contributed to the intervention content. Access to data is limited to AT, PM, PK and HK unless requested by others. All the authors read and approved the final manuscript.

\section{Funding}

Health Centre of Jyväskylä Cooperation Area and Primary Health Care Unit of Northern Savo Hospital District have participated in funding of the present study. The funders did not take part in the study design, data collection and analysis or preparation and publishing of the manuscript.

\section{Availability of data and materials}

The datasets generated and analysed during the current study are not publicly available due to protection of individual privacy, but are available from the corresponding author on reasonable request.

\section{Ethics approval and consent to participate}

Permission to access raw data was obtained from the research committee of Health Centre of Jyväskylä Cooperation Area.

\section{Consent for publication}

Not applicable.

\section{Competing interests}

The authors declare that they have no competing interests.

\section{Author details}

${ }^{1}$ University of Eastern Finland, Institute of Public Health and Clinical Nutrition, Kuopio, Finland. ${ }^{2}$ Health Centre of Jyväskylä Cooperation Area, Jyväskylä, Finland. ${ }^{3}$ University of Turku, Turku, Finland. ${ }^{4}$ Medcare Oy, Äänekoski, Finland. ${ }^{5}$ National Institute for Health and Welfare, Helsinki, Finland. ${ }^{6}$ Department of Medicine, Turku University Hospital and University of Turku, Turku, Finland. ${ }^{7}$ Primary Health Care Unit, Kuopio University Hospital, Kuopio, Finland. 
Received: 20 September 2019 Accepted: 6 April 2020

Published online: 14 April 2020

\section{References}

1. Neaton JD, Blackburn H, Jacobs D, Kuller L, Lee DJ, Sherwin R, Shih J, Stamler J, Wentworth D. Serum cholesterol level and mortality findings for men screened in the multiple risk factor intervention trial. Multiple risk factor intervention trial research group. Arch Intern Med. 1992;152(7):1490500.

2. Prospective Studies Collaboration, Lewington S, Whitlock G, Clarke R, Sherliker P, Emberson J, Halsey J, Qizilbash N, Peto R, Collins R. Blood cholesterol and vascular mortality by age, sex, and blood pressure: a metaanalysis of individual data from 61 prospective studies with 55,000 vascular deaths. Lancet. 2007;370(9602):1829-39.

3. Authors/Task Force Members, Catapano AL, Graham I, De Backer G, Wiklund O, Chapman MJ, Drexel H, Hoes AW, Jennings CS, Landmesser U, Pedersen TR, Reiner Z, Riccardi G, Taskinen MR, Tokgozoglu L, Verschuren WM, Vlachopoulos C, Wood DA, Zamorano JL. 2016 ESC/EAS guidelines for the Management of Dyslipidaemias: the task force for the Management of Dyslipidaemias of the European Society of Cardiology (ESC) and European atherosclerosis society (EAS) developed with the special contribution of the European Assocciation for Cardiovascular Prevention \& Rehabilitation (EACPR). Atherosclerosis. 2016;253:281-344.

4. Gould AL, Davies GM, Alemao E, Yin DD, Cook JR. Cholesterol reduction yields clinical benefits: meta-analysis including recent trials. Clin Ther. 2007; 29(5):778-94.

5. Karmali KN, Lloyd-Jones DM, Berendsen MA, Goff DC, Sanghavi DM, Brown NC, Korenovska L, Huffman MD. Drugs for primary prevention of Atherosclerotic cardiovascular disease: an overview of systematic reviews. JAMA Cardiol. 2016;1(3):341-9.

6. Taylor F, Huffman MD, Macedo AF, Moore TH, Burke M, Davey Smith G, Ward K, Ebrahim S. Statins for the primary prevention of cardiovascular disease. Cochrane Database Syst Rev. 2013;1:CD004816.

7. Cholesterol Treatment Trialists' (CTT) Collaboration, Baigent C, Blackwell L, Emberson J, Holland LE, Reith C, Bhala N, Peto R, Barnes EH, Keech A, Simes J, Collins R. Efficacy and safety of more intensive lowering of LDL cholesterol: a meta-analysis of data from 170,000 participants in 26 randomised trials. Lancet. 2010;376(9753):1670-81.

8. Costa J, Borges M, David C, Vaz Carneiro A. Efficacy of lipid lowering drug treatment for diabetic and non-diabetic patients: meta-analysis of randomised controlled trials. BMJ. 2006:332(7550):1115-24.

9. Williams B, Mancia G, Spiering W, Agabiti Rosei E, Azizi M, Burnier M, Clement DL, Coca A, de Simone G, Dominiczak A, Kahan T, Mahfoud F, Redon J, Ruilope L, Zanchetti A, Kerins M, Kjeldsen SE, Kreutz R, Laurent S, Lip GYH, McManus R, Narkiewicz K, Ruschitzka F, Schmieder RE, Shlyakhto E, Tsioufis C, Aboyans V, Desormais I, ESC scientific document group. 2018 ESC/ESH guidelines for the management of arterial hypertension. Eur Heart J. 2018:39(33):3021-104.

10. Borodulin $\mathrm{K}$, Vartiainen $\mathrm{E}$, Peltonen $\mathrm{M}$, Jousilahti $\mathrm{P}$, Juolevi A, Laatikainen T, Mannisto S, Salomaa V, Sundvall J, Puska P. Forty-year trends in cardiovascular risk factors in Finland. Eur J Pub Health. 2015;25(3):539-46.

11. Kotseva K, De Bacquer D, De Backer G, Ryden L, Jennings C, Gyberg V Abreu A, Aguiar C, Conde AC, Davletov K, Dilic M, Dolzhenko M, Gaita D, Georgiev B, Gotcheva N, Lalic N, Laucevicius A, Lovic D, Mancas S, Milicic D, Oganov R, Pajak A, Pogosova N, Reiner Z, Vulic D, Wood D, On Behalf Of The Euroaspire, Investigators. Lifestyle and risk factor management in people at high risk of cardiovascular disease. A report from the European Society of Cardiology European Action on Secondary and Primary Prevention by Intervention to Reduce Events (EUROASPIRE) IV crosssectional survey in 14 European regions. Eur J Prev Cardiol. 2016;23(18): 2007-18.

12. Ho LT, Yin WH, Chuang SY, Tseng WK, Wu YW, Hsieh IC, Lin TH, Li YH, Huang LC, Wang KY, Ueng KC, Fang CC, Pan WH, Yeh HI, Wu CC, Chen JW, Taiwanese secondary prevention for patients with AtheRosCLErotic disease (T-SPARCLE) registry investigators. Determinants for achieving the LDL-C target of lipid control for secondary prevention of cardiovascular events in Taiwan. PLoS One. 2015;10(3):e0116513.

13. Jones PH, Nair R, Thakker KM. Prevalence of dyslipidemia and lipid goal attainment in statin-treated subjects from 3 data sources: a retrospective analysis. J Am Heart Assoc. 2012;1(6):e001800.
14. Russo G, Pintaudi B, Giorda C, Lucisano G, Nicolucci A, Cristofaro MR, Suraci C, Mulas MF, Napoli A, Rossi MC, Manicardi V. Age- and gender-related differences in LDL-cholesterol Management in Outpatients with type 2 diabetes mellitus. Int J Endocrinol. 2015;2015:957105.

15. Ambrose JA, Najafi A. Strategies for the prevention of coronary artery disease complications: can we do better? Am J Med. 2018;131(9):1003-9.

16. Domanski MJ, Fuster V, Diaz-Mitoma F, Grundy S, Lloyd-Jones D, Mamdani M, Roberts R, Thorpe K, Hall J, Udell JA, Farkouh ME. Next steps in primary prevention of coronary heart disease: rationale for and design of the ECAD trial. J Am Coll Cardiol. 2015;66(16):1828-36.

17. Hippisley-Cox J, Coupland C, Robson J, Brindle P. Derivation, validation, and evaluation of a new QRISK model to estimate lifetime risk of cardiovascular disease: cohort study using QResearch database. BMJ. 2010;341:c6624.

18. Berry JD, Dyer A, Cai X, Garside DB, Ning H, Thomas A, Greenland P, Van Horn L, Tracy RP, Lloyd-Jones DM. Lifetime risks of cardiovascular disease. N Engl J Med. 2012;366(4):321-9.

19. Niiranen TJ, McCabe EL, Larson MG, Henglin M, Lakdawala NK, Vasan RS, Cheng S. Heritability and risks associated with early onset hypertension: multigenerational, prospective analysis in the Framingham heart study. BMJ. 2017;357:j1949.

20. The medical research decree of 1999, Pub. L. No. 986 of 1999. Finnish.

21. Anonymous ICD-10. International Statistical Classification of Diseases and Related Health Problems, 10th revision. 2011.

22. Levey AS, Stevens LA, Schmid CH, Zhang YL, Castro AF, Feldman HI, Kusek JW, Eggers P, Van Lente F, Greene T, Coresh J, CKD-EPI (chronic kidney disease epidemiology collaboration). A new equation to estimate glomerular filtration rate. Ann Intern Med. 2009;150(9):604-12.

23. Anonymous. Update on current care guideline: dyslipidaemias. Duodecim. 2013;129(11):1198-9.

24. Sabate E. Adherence to long-term therapies: Evidence for action; 2003.

25. Rodondi N, Peng T, Karter AJ, Bauer DC, Vittinghoff E, Tang S, Pettitt D, Kerr EA, Selby JV. Therapy modifications in response to poorly controlled hypertension, dyslipidemia, and diabetes mellitus. Ann Intern Med. 2006; 144(7):475-84.

26. Zamora A, Fernandez de Bobadilla F, Carrion C, Vazquez G, Paluzie G, Elosua R, Vilaseca M, Martin-Urda A, Rivera A, Plana N, Masana L, VALIDA study group, network of lipid units of Catalonia (XULA). Pilot study to validate a computer-based clinical decision support system for dyslipidemia treatment (HTE-DLP). Atherosclerosis. 2013;231(2):401-4.

27. Alagoz E, Chih MY, Hitchcock M, Brown R, Quanbeck A. The use of external change agents to promote quality improvement and organizational change in healthcare organizations: a systematic review. BMC Health Serv Res. 2018; 18(1):42-018.

28. Kokko S, Virta L, Vehko $T$. The roles and relative contributions of municipal health centres and alternative service providers in the management of type 2 diabetes and hypertension in Finland. Finnish Med J. 2015;70(44):2945-9.

29. Abbott RD, Garrison RJ, Wilson PW, Epstein FH, Castelli WP, Feinleib M, LaRue C, Joint distribution of lipoprotein cholesterol classes. The Framingham study. Arteriosclerosis. 1983;3(3):260-72.

30. Morgan AE, Mooney KM, Wilkinson SJ, Pickles NA, Mc Auley MT. Cholesterol metabolism: a review of how ageing disrupts the biological mechanisms responsible for its regulation. Ageing Res Rev. 2016;27:108-24.

31. Halava H, Huupponen R, Pentti J, Kivimaki M, Vahtera J. Predictors of firstyear statin medication discontinuation: a cohort study. J Clin Lipidol. 2016; 10(4):987-95.

32. Kreisberg RA, Kasim S. Cholesterol metabolism and aging. Am J Med. 1987; 82(1B):54-60.

33. Siven SS, Niiranen TJ, Aromaa A, Koskinen S, Jula AM. Social, lifestyle and demographic inequalities in hypertension care. Scand J Public Health. 2015; 43(3):246-53.

34. Hippisley-Cox J, Coupland C, Brindle P. Development and validation of QRISK3 risk prediction algorithms to estimate future risk of cardiovascular disease: prospective cohort study. BMJ. 2017;357:j2099.

\section{Publisher's Note}

Springer Nature remains neutral with regard to jurisdictional claims in published maps and institutional affiliations. 